Military Technical College

Kobry El-Kobbah,

Cairo, Egypt.

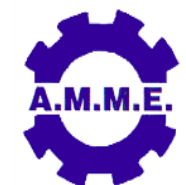

$18^{\text {th }}$ International Conference

on Applied Mechanics and

Mechanical Engineering.

\title{
MATHEMATICAL MODEL TO SIMULATE THE HEAT TRANSFER IN VITRIFIED CLAY PIPES KILN
}

\author{
H. A. Refaey ${ }^{1}$, M. A. Karali ${ }^{2}$, A. G. Al-Hasnawi ${ }^{3}$ and E. Specht ${ }^{4}$
}

\begin{abstract}
Carrying out experiments in tunnel kilns are difficult and costly. Due to the large length of such kilns that sometimes reaches 180 meters. That causes the production cycle takes some days. Therefore, a mathematical model is needed to simulate the heat transfer process in such kilns. In this contribution, a simple shape product (vitrified clay pipes) was used in the modeling, in order to simplify the complexity of the process. The bvp4c code was used to solve all ordinary differential equations (ODEs) of the model to obtain temperature profiles of the system using Matlab. Results revealed that: the excess air number has a higher impact on the heat transfer process inside the kiln. Consequently, the thermal heating of products could be easily controlled, by changing the excess air values. Heat transfer coefficient enhancement is a key parameter to save the energy consumption within the kiln.
\end{abstract}

\section{KEYWORDS}

Tunnel kiln, Vitrified clay pipes, Mathematical model, Energy consumption, Heat transfer, Firing zone

1 Mechanical Power Engineering Department, Faculty of Engineering at Shoubra, Benha Univ., Cairo, Egypt. E-mail address: hassanein.refaey@feng.bu.edu.eg.

2 Department of Mechanical Engineering, Faculty of Engineering and Technology, Future University in Egypt, 90 St., New Cairo, Egypt.

3 Electromechanical Engineering, University of Technology, Baghdad, Tal Muhammad 10066, Baghdad, Iraq.

4 Institute of Fluid Dynamics and Thermodynamics, Otto von Guericke University, Magdeburg, Universitätsplatz 2 D-39106 Magdeburg, Germany. 


\section{NOMENCLATURES}

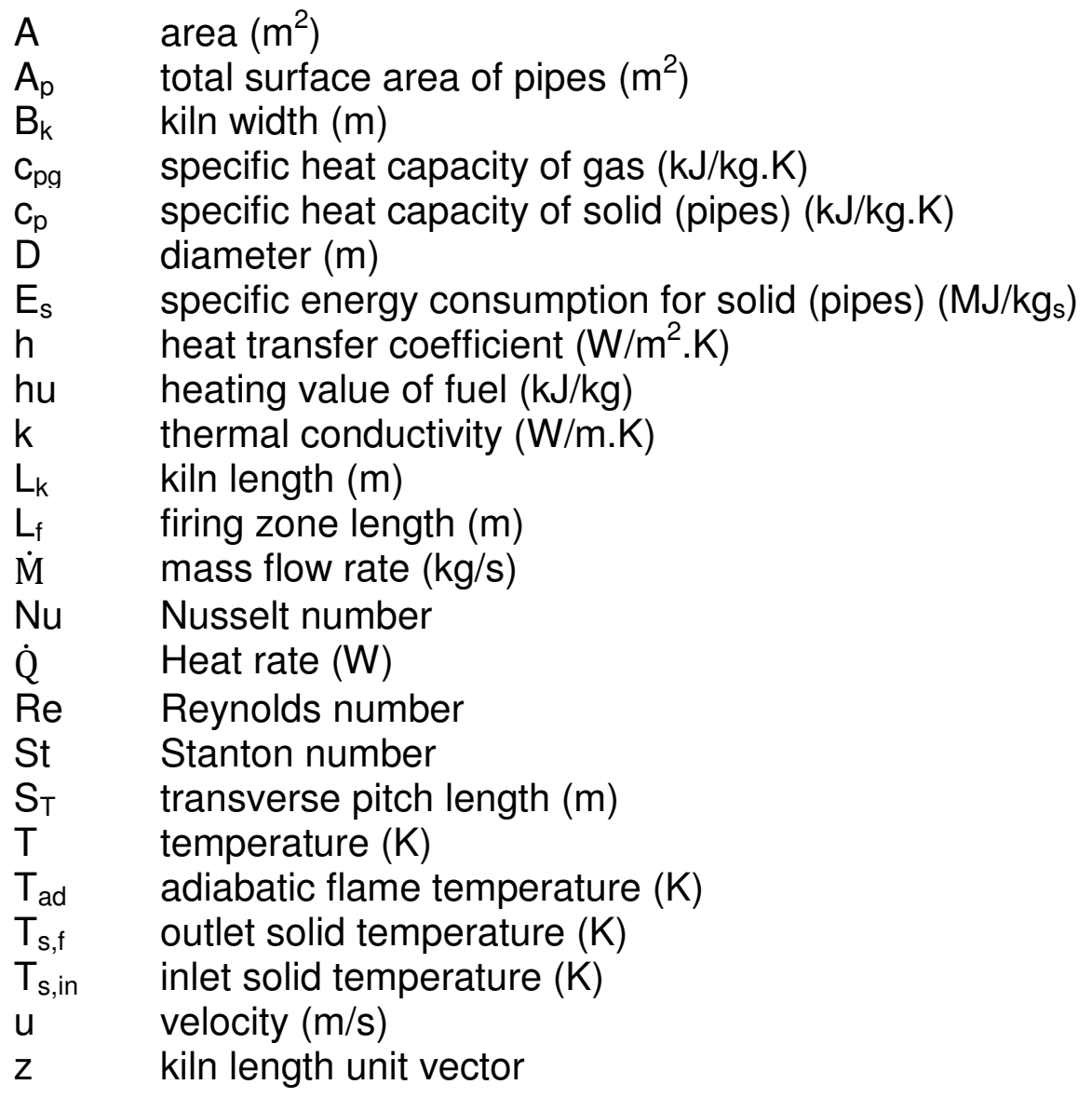

\section{Subscript}

a air

conv convection

g gas

$\mathrm{p} \quad$ pipe

rad radiation

t total

Greek letters

$\varepsilon \quad$ emissivity

$\lambda$ excess air number

$\sigma \quad$ Stephan Boltzmann constant

$v \quad$ kinematic viscosity $\left(\mathrm{m}^{2} / \mathrm{s}\right)$

$\rho \quad$ density $\left(\mathrm{kg} / \mathrm{m}^{3}\right)$

\section{INTRODUCTION}

Ceramics industry especially for vitrified clay pipes production, consumes a lot of energy. Therefore, reducing the energy consumption needed for this industry is very important issue. Tunnel kilns are used for the production of vitrified clay pipes. This type of kilns is considered as one of continuously operated kilns in the firing process. The pipes enter and transported through the kiln on a kiln car. Pipes are supported on the car by a kiln furniture. The vitrified clay pipes are preheated in the preheating zone and heated up to its sintering temperature in the burning zone. It is then cooled 
down in the kiln cooling zone to a temperature near the room temperature before exit.

Some papers are available in literature that discussing research in this field as follows. Dugwell and Oakley [1] obtained a correlation for convective heat transfer rates calculation in refractory firing. A valuable information for convective heat transfer in brick tunnel kiln has been provided by Abou-Ziyan [2]. Former researchers provided mathematical models to predict gas temperature in tunnel kilns [3-6]. Mancuhan et al. [4] developed a 1-D model for drying bricks simulation in the preheating zone of a tunnel kiln. Gol'tsova et al. [5] presented a mathematical model for the process parameters in real-time as a function of the manufactured bricks. The results showed that there was a high power consumption. Durakovic and Delalic [6] investigated the temperature fields in a tunnel kiln for brick production. A software was developed to represent the brick temperature distribution in the furnace during its production process in real conditions.

A numerical simulation for glost firing of porcelain was investigated by Becker et al. [7]. A commercial CFD-code was used. Possamai et al. [8] simulated the thermal process inside a ceramic Frits melting kiln with CFD and a global FORTRAN code. The numerical results was compared with experimental data. The comparison revealed that the numerical simulation were consistent with the real phenomena. Mancuhan and Kucukada [9] presented fuel and air optimization in a bricks tunnel kiln. The admixed coal with high calorific value was recommended when the natural gas was used as the fuel in the firing zone. Kaya et al. [10] presented an optimization of the firing zone to minimize the fuel cost. The model was represented heat transfer phenomena in simple form.

Refaey and Specht [11] presented a CFD simulation to visualize the flue field in the sanitary ware kiln. Ana Mezquita et al. [12] studied the energy saved in the tile kiln when recovered part of the cooling gases in the firing chamber. A $17 \%$ of energy saving have been reported. Oba et al. [13] presented a 3-D numerical model for a roof tiles kiln, fueled by firewood and shale oil. The experimental data was compared with the numerical results and a good agreement was observed. Refaey et al. [14 and 15] presented a 1-D mathematical model to simulate the process in preheating and burning zones in tunnel kilns for burning of ceramics. Moreover, the influence of fuel distribution along the firing zone on the temperature profiles was studied. The results demonstrated that the energy consumption was always increases progressively with the firing zone length. The results revealed, to reduce the energy consumption, the firing zone length should be as short as possible.

Recently, Soussi et al. [16] optimized the recovered air mass flow from the cooling zone to the firing zone to reduce the natural gas consumption during the manufacturing of hollow bricks in a Tunisian tunnel kiln. The results showed that the existence of an optimal value of the recovered air mass flow that could reduce the actual daily consumption of the natural gas up to $4.6 \%$. Redemann and Specht [17] used a mathematical model to simulate the roof tiles tunnel kiln process. The results showed that the required mean flow velocity through the roof tiles setting should be in the range of $20 \mathrm{~m} / \mathrm{s}$. Refaey et al. [18] experimentally investigated the effect of guide vanes with attack angles $\left(\theta=120^{\circ}, 135^{\circ}\right.$, and $\left.150^{\circ}\right)$ on the cooling of bricks inside tunnel kiln. The results demonstrated that the heat transfer and pressure drop depends on the brick setting. Furthermore, the guide vanes increased the heat 
transfer rates with all settings. The maximum enhancement of about $94.5 \%$ was obtained for longitudinal brick at middle column (compared with that nearest to the wall) in setting 2 at $\theta=135^{\circ}$ and $R e=22,407$. Finally, Nusselt number correlation was represented within $11,867 \leq \operatorname{Re} \leq 25,821,0.33 \leq(\mathrm{S} / \mathrm{a}) \leq 1.0,0.79 \leq(\varepsilon S / b) \leq 3.0$, and $120^{\circ} \leq \theta \leq 180^{\circ}$.

It could be concluded from literature that: experimental results by former researchers concentrated on brick tunnel kilns. Mathematical models are not clear enough. Hence, the current paper represented a mathematical model to understand the main process and heat transfer mechanism in tunnel kilns using simple product shape of vitrified clay pipes.

\section{MODEL DESCRIPTION}

The heat transfer mechanism varies from one kiln to another. The mechanism complexity depends on: product type, shape and its interaction with kiln car and kiln furniture. Based on that, it is important to study the heat transfer for a simple shape product. Therefore, vitrified clay pipes kiln is used in the present work to analyze the heat transfer mechanism. Basically, the tunnel kiln has three zones: preheating zone, firing zone and cooling zone. In the present paper, the mathematical model was basically done for the preheating and firing zones. A schematic description of the vitrified clay pipes kiln with gas distribution along the firing zone length is shown in Fig. 1. From the figure, the combustion of fuel with air is occurred in an adiabatic combustion chamber. Therefore, the outlet gas temperature from this combustion process can be considered as the adiabatic flame temperature. As demonstrated in the figure, the pipes are carried on kiln car in counter direction to gas flow. Therewith, the kiln process is reduced to a simple counter current heat exchanger. In addition, Fig. 2 shows the cross sectional view for the kiln in simple case without kiln car. The figure shows that gases enter the kiln from the side burners. Definitely, the main source for the gases is the combustion gases which come from the burners.

\section{Energy Balance}

The model presented in this paper is done for only two zones; preheating and burning zones. In the model, the solid material (pipes) is heated up to the required sintering temperature. Herein, the energy from fossil fuel is the required energy for the total heating process in the kiln. Therefore, the following assumptions have to be made to the present model. Steady state process, product and gas temperatures are constant at any cross section, the fuel is uniformly distributed along the firing zone length $\mathrm{L}_{f}$, heat losses is neglected and all material properties are constant. The equations for the basic process of heat transfer were represented by Refaey [15].

\section{Heat Transfer Modeling of Vitrified Clay Pipes}

From the previous description of the kiln and gas flows inside, the heat is transferred from the gas to the pipes by convection and radiation. Due to gas motion through the vitrified clay pipes the heat is transferred from the gas by convection and it also radiates heat to the vitrified clay pipes. The details of these two types of heat transfer inside the kiln are presented below for the vitrified clay pipes kiln. 


\section{Convective heat transfer analysis}

Herein, there are two arrangements for the pipes. The staggered arrangement and the in-line arrangement are as shown in Fig. 3. To calculate the convective heat transfer coefficient, the following approach is used.

Reynolds number can be calculated from the basic calculations of cross flow over tube banks from Eq. (1) [19]. The gas properties are taken as constant values. The value of Reynolds number in cross flow calculations based on the maximum velocity $U_{\text {max,i }}$ which is based on the arrangement.

$\operatorname{Re}=\frac{U_{\max } \mathrm{D}}{\mathrm{u}}$

where, $D$ is the diameter of vitrified clay pipes. The maximum velocity is calculated from the following equation:

$\mathrm{U}_{\max }=\frac{\mathrm{S}_{\mathrm{T}}}{\mathrm{S}_{\mathrm{T}}-\mathrm{D}} \mathrm{u}_{\mathrm{g}}$

The transverse pitch $\left(\mathrm{S}_{\mathrm{T}}\right)$ depends on the arrangement as represents in Fig. 3. The gas velocity could be calculated from the following equation:

$u_{g}=\frac{\dot{M}_{g}}{\rho B_{k} H_{k}}$

Finally, the Nusselt number is calculated as follow:

$N u=\frac{h D}{k}$

Consequently, the differential equation which used to calculate the change in convective heat transfer is as following:

$\mathrm{dQ} \dot{\mathrm{Q}}_{\mathrm{conv}}=\mathrm{h}_{\mathrm{conv}} \mathrm{A}_{\mathrm{p}}\left(\mathrm{T}_{\mathrm{g}}-\mathrm{T}_{\mathrm{s}}\right) \mathrm{dz}$

\section{Radiative heat transfer analysis}

The radiation depends on the emissivity of gas and solid material. There are two main gases in the combustion gases; $\mathrm{CO}_{2}$ and $\mathrm{H}_{2} \mathrm{O}$. Therefore, calculating the emissivity of the mixture of the two gases is important. So that, an approximated equation is used in Matlab program to determine the gas mixture emissivity. The approximated Eqn. (6) [20] is used to calculate the gas emissivity of the two gases.

$\varepsilon_{g_{i}}=\mathrm{A}_{\mathrm{b}} \exp ^{-\mathrm{B}_{\mathrm{b}} T}$

where, $A_{b}$ and $B_{b}$ are functions in beam length and partial pressure for carbon dioxide and water vapor. The temperature of the gas, $\mathrm{T}$, is in Kelvin degree.

Then the total emissivity could be calculated from this equation:

$\varepsilon_{\mathrm{g}}=\varepsilon_{\mathrm{CO}_{2}}+\varepsilon_{\mathrm{H}_{2} \mathrm{O}}-\varepsilon_{\mathrm{CO}_{2}} \varepsilon_{\mathrm{H}_{2} \mathrm{O}}$

The following equation represents the change in radiative heat transfer.

$\mathrm{d} \dot{\mathrm{Q}}_{\mathrm{rad}}=h_{r} \mathrm{~A}_{\mathrm{p}}\left(\mathrm{T}_{\mathrm{g}}-\mathrm{T}_{\mathrm{s}}\right) \mathrm{dz}$ 
One of the approximated forms of the radiative heat transfer coefficient is represented in Eqn. (9). It is represented as a function of effective emissivity and both gas and solid temperatures.

$h_{r}=\varepsilon \sigma \mathrm{T}_{g}^{3}\left\lfloor 1+\left(\frac{\mathrm{T}_{\mathrm{s}}}{\mathrm{T}_{\mathrm{g}}}\right)+\left(\frac{\mathrm{T}_{\mathrm{s}}}{\mathrm{T}_{\mathrm{g}}}\right)^{2}+\left(\frac{\mathrm{T}_{\mathrm{s}}}{\mathrm{T}_{\mathrm{g}}}\right)^{3}\right\rfloor$

where, $\varepsilon$ is the effective emissivity between the gas mixture and solid material can be calculated as follow:

$\varepsilon=\frac{1}{\frac{1}{\varepsilon_{\mathrm{p}}}+\frac{1}{\varepsilon_{\mathrm{g}}}-1}$

Then the total heat transfer and the combined heat transfer coefficient could be obtained as:

$\mathrm{d} \dot{\mathrm{Q}}_{g \rightarrow p}=\mathrm{d} \dot{\mathrm{Q}}_{\text {conv }}+\mathrm{d} \dot{\mathrm{Q}}_{\mathrm{rad}}$

$\mathrm{h}_{t}=\mathrm{h}_{\text {conv }}+\mathrm{h}_{r}$

\section{Ordinary Differential Equations}

In the present study, the temperature profile of the solid (vitrified clay pipes) and the gas is calculated by using the energy balance for a differential kiln length $\mathrm{dz}$. The basic analysis for only convective heat transfer has been done by Refaey et al. [14 and 15].

Herein, there is an additional term impeded in the equations related to radiative term. Therefore, the ODEs for solid (pipes) and gas are represents as follow with these two boundary conditions $\mathrm{T}_{\mathrm{s}(\mathrm{z}=0)}=\mathrm{T}_{\mathrm{s}, \mathrm{in}}$ and $\mathrm{T}_{\mathrm{s}(\mathrm{z}=\mathrm{Lk})}=\mathrm{T}_{\mathrm{s}, \mathrm{f}}$.

The analysis has been done for the kiln to obtain the temperature profile equations. The following first order ordinary differential equation (ODE) is for solid:

$\frac{d T_{p}}{d z}=\frac{h_{t} A_{p}}{\dot{M}_{p} c_{p}}\left(T_{g}-T_{p}\right)$.

For the gas equation, there are two zones; preheating and burning. Consequently, there are two ODEs for the gas.

The gas equation for the preheating zone is as follow:

$\frac{\mathrm{dT}_{\mathrm{g}}}{\mathrm{dz}}=\frac{\mathrm{h}_{\mathrm{t}, \mathrm{pre}} \mathrm{A}_{\mathrm{p}}}{\dot{\mathrm{M}}_{\mathrm{g}} \mathrm{c}_{\mathrm{pg}}}\left(\mathrm{T}_{\mathrm{g}}-\mathrm{T}_{\mathrm{p}}\right)$.

The gas equation for the burning zone is obtained as follow; 


$$
(1-\mathrm{z}) \frac{\mathrm{dT}_{\mathrm{g}}}{\mathrm{dz}}=\frac{\mathrm{h}_{\mathrm{t}, \mathrm{bur}} \mathrm{A}_{\mathrm{p}}}{\dot{\mathrm{M}}_{\mathrm{g}} \mathrm{c}_{\mathrm{pg}}} \frac{\mathrm{L}_{\mathrm{f}}}{\mathrm{L}_{\mathrm{k}}}\left(\mathrm{T}_{\mathrm{g}}-\mathrm{T}_{\mathrm{p}}\right)-\left(\mathrm{T}_{\mathrm{ad}}-\mathrm{T}_{\mathrm{g}}\right) .
$$

where, $T_{g, i n}=T_{a d}$, and $T_{a d}$ is the adiabatic flam temperature which is calculated from this equation:

$\mathrm{T}_{\mathrm{ad}}=\frac{\mathrm{hu}}{\mathrm{c}_{\mathrm{pg}}(1-\lambda \mathrm{L})}+\mathrm{T}_{\mathrm{a}}$,

And the Stanton number for solid and gas $\left(\mathrm{St}_{\mathrm{s}}, \mathrm{St}_{\mathrm{g}}\right)$ are defined as:

$\mathrm{St}_{\mathrm{p}}=\frac{\mathrm{h}_{\mathrm{t}} \mathrm{A}_{\mathrm{p}}}{\dot{\mathrm{M}}_{\mathrm{p}} \mathrm{c}_{\mathrm{p}}} \quad$ and $\quad \mathrm{St}_{\mathrm{g}}=\frac{\mathrm{h}_{\mathrm{t}} \mathrm{A}_{\mathrm{p}}}{\dot{\mathrm{M}}_{\mathrm{g}} \mathrm{c}_{\mathrm{pg}}}$

The physical data and boundary conditions are inserted into the commercial code (pvb4c) program with two known boundary conditions (inlet temperature of solid $\mathrm{T}_{\text {s.in }}$, and outlet solid temperature $T_{s . f}$ ). The temperature profiles resulted from the program for the gas and solid along the preheating and firing zones are obtained. Some variables used in solving this system are listed in Table 1.

\section{RESULTS AND DISCUSSIONS}

The ODEs equations are solved the vitrified clay pipes by MATLAB program. The ODE of solid (pipes) in the two zones is represents by Eqn. (13). On the other hand, there are two equations for gas depends on the zone. Eqns. (14 - 15) are used for the preheating and firing zones, respectively.

The energy consumption obtained from the model is shown in Fig. 4 as a function in Stanton number for the pipes with different excess air numbers. It can be noticed that the energy consumption decreases as Stanton number increases for all excess air numbers. Consequently, for any small increase in Stanton number (heat transfer) results in a big decrease of energy consumption, Ep, for same excess air number. Furthermore, the figure illustrates that, the energy consumption increases as excess air number increases for the same Stanton number. The shadow part in Fig. 4 represents the industrial energy consumption range.

Figure 5 represents the temperature profile along the preheating and firing zones with different excess air numbers and the corresponding Stanton number. It can be noticed that, the slope of the temperature profile for gas changes from the firing to the preheating zone. Regarding the temperature profile of the pipes, there is no noticeable effect of the excess air number on the profile. The Fig. shows that, as the excess air number decreases the energy consumption increases. This is due to higher flue gas temperature.

Herein, Figure 6 shows the effect of excess air number on temperature distribution at constant energy consumption. From the figure as the excess air number decrease the flue gases temperature increases. The temperature of the solid is nearly linear along the two zones for the small values of excess air $(\lambda<1.7)$. The figure demonstrates that, for higher values of $\lambda$ the temperature profile of the solid is 
affected by the excess air value. Therefore, during the production process of the vitrified clay pipes, the excess air value should be controlled.

Figure 7 illustrates the effect of Stanton number on temperature distribution along the kiln for constant excess air number. The figure shows that as the Stanton number decreases the temperature of flue gases increases due to highly energy consumption. The energy consumption values are illustrated in Fig. 4. The temperature of the solid is nearly linear along the two zones and there is no effect of the Stanton number on the temperature profile.

\section{CONCLUSION}

The present paper represents a mathematical model to simulate the process in a vitrified clay pipes kiln. The model represents the ordinary differential equations for solids and gas in the preheating and firing zones. Solving for the temperature profiles at different operating conditions of: excess air number and Stanton number. Showing the influences on the energy consumption of the kiln. The model represents the heat transfer in the kiln in presence of two modes; convection and radiation. The conclusions from this work are represented in the following points:

- As the Stanton number increase the energy consumption decreases.

- The excess air number has a high influence on the heat transfer inside the kiln. Increasing the excess air number increases the energy consumption, as a result, flue gas temperature increases.

- Therefore, the excess air value effect on gas and solid temperature profiles. As a consequence, it could be used to control the thermal heating of the products.

- It can be concluded that at lower excess air number with higher Stanton number, a lower flue gas temperature is obtained which is important for chimney design.

- For the vitrified clay pipes kiln it is of great importance to change the pipes arrangement to allow gas passage between the pipes. In order to enhance amount of heat transfer and decreasing energy consumption.

- Increasing heat transfer coefficient gives high potential to save energy consumption.

\section{REFERENCES}

[1] D. R. Dugwell and D. E. Oakley, "Correlation of connective heat transfer data for tunnel kilns", ZI, Ziegelindustrie International/Brick and Tile Industry International, Vol. 42, No. 10, pp. 536 - 545 (1989).

[2] H. Z. Abou-Ziyan, "Convective heat transfer from different brick arrangements in tunnel kilns", Applied Thermal Engineering, Vol. 24, No. 2-3, pp. 171 - 191 (2004).

[3] D. R. Dugwell and D.E. Oakley, "Simulation of tunnel kilns for firing refractory products, British ceramic", Transactions and journal, Vol. 86, No. 5, pp. 50 153 (1987).

[4] E. Manuhan, K. Kkada, and E. Alpman, "Mathematical modeling and simulation of the preheating zone of a tunnel kiln", ISI BilimiVeTeknigiDergisi, Journal of Thermal Science and Technology, Vol. 31, No. 2, pp. $79-86$ (2011). 
[5] O. B. Gol'tsova, V. S. Klekovkin, V. A. Tenenev, "Development and approval of a mathematical model of a brick firing kiln", Glass and Ceramics (English translation of StekloiKeramika), Vol. 65, No. 3-4, pp.100 - 102 (2008).

[6] J. Durakovic and S. Delalic, "Temperature field analysis of tunnel kiln for brick production", RMZ - Materials and Geo environment, Vol. 53, No. 3, pp. 403 - 408 (2006).

[7] F. H. Becker, G. Walter and L. Lorenz, "Heat exchange in a fast fringe kiln for glost firing of porcelain", CFI Ceramic Forum International, Vol. 83, No. 9, pp. E59 - E65 (2006).

[8] T. S. Possamai, R. Oba, V. Nicolau and O. Otte, "Numerical simulation of a ceramic kiln used in frits production", in 20th International Congress of Mechanical Engineering, Gramado, RS, Brazil COB09 1152, November (2009).

[9] E. Mancuhan and K. Kucukada, "Optimization of fuel and air use in a tunnel kiln to produce coal admixed bricks", Applied Thermal Engineering, Vol. 26, No.14-15, pp. 1556 - 1563 (2006).

[10] S. Kaya, E. Mancuhan, and K. Kücükada, "Modeling and optimization of the firing zone of a tunnel kiln to predict the optimal feed locations and mass fluxes of the fuel and secondary air", Applied Energy, Vol. 86, No. 3, pp. 325 - 332 (2009).

[11] H. A. Refaey, E. Specht, "Flow field visualization to simulate the burning of sanitary ware in tunnel kilns", Proceedings of ICFD11: Eleventh International Conference of Fluid Dynamics, Alexandria, Egypt, December 19-21 (2013)

[12] A. Mezquita, J. Boix, E. Monfort and G. Mallol, "Energy saving in ceramic tile kilns: Cooling gas heat recovery", Applied Thermal Engineering, Vol. 65, No.1-2, pp. 102 - 110 (2014).

[13] R. Oba, T.S. Possamai and V.P. Nicolau, "Thermal analysis of a tunnel kiln used to produce roof tiles", Applied Thermal Engineering, Vol. 63, No. 1, 5, pp. 59 - 65 (2014).

[14] H. A. Refaey, E. Specht and M. R. Salem, "Influence of Fuel Distribution and Heat Transfer on Energy Consumption in Tunnel Kilns", International Journal of Advances in Engineering \& Technology, June (2015).

[15] H. A. Refaey, "Mathematical model to analyze the heat transfer in tunnel kilns for burning of ceramics", Ph.D. dissertation. Magdeburg, Germany: Otto- von Guericke University (2013).

[16] N. Soussi, W. Kriaa, H. Mhiri and Ph. Bournot, "Reduction of the energy consumption of a tunnel kiln by optimization of the recovered air mass flow from the cooling zone to the firing zone", Applied Thermal Engineering, Vol. 124, pp. 1382 - 139 (2017).

[17] T. Redemann and E. Specht, "Mathematical model to investigate the influence of circulation systems on the firing of ceramics", Energy Procedia, Vol. 120 , pp. 620-627 (2017).

[18] H. A. Refaey, A. A. Abdel-Aziz, R. K. Ali, H. E. Abdelrahman and M. R. Salem, "Augmentation of convective heat transfer in the cooling zone of brick tunnel kiln using guide vanes: An experimental study", International Journal of Thermal Sciences, Vol. 122, pp. 172 - 185 (2017).

[19] Y. A. Cengel and A. J. Ghajar, "Heat and Mass Transfer: Fundamentals and Applications", McGraw-Hill (2011).

[20] E. Specht, "Lecture Notes of: Advanced heat and mass transfer", Otto VonGuericke University, Magdeburg, Germany, (2008). 


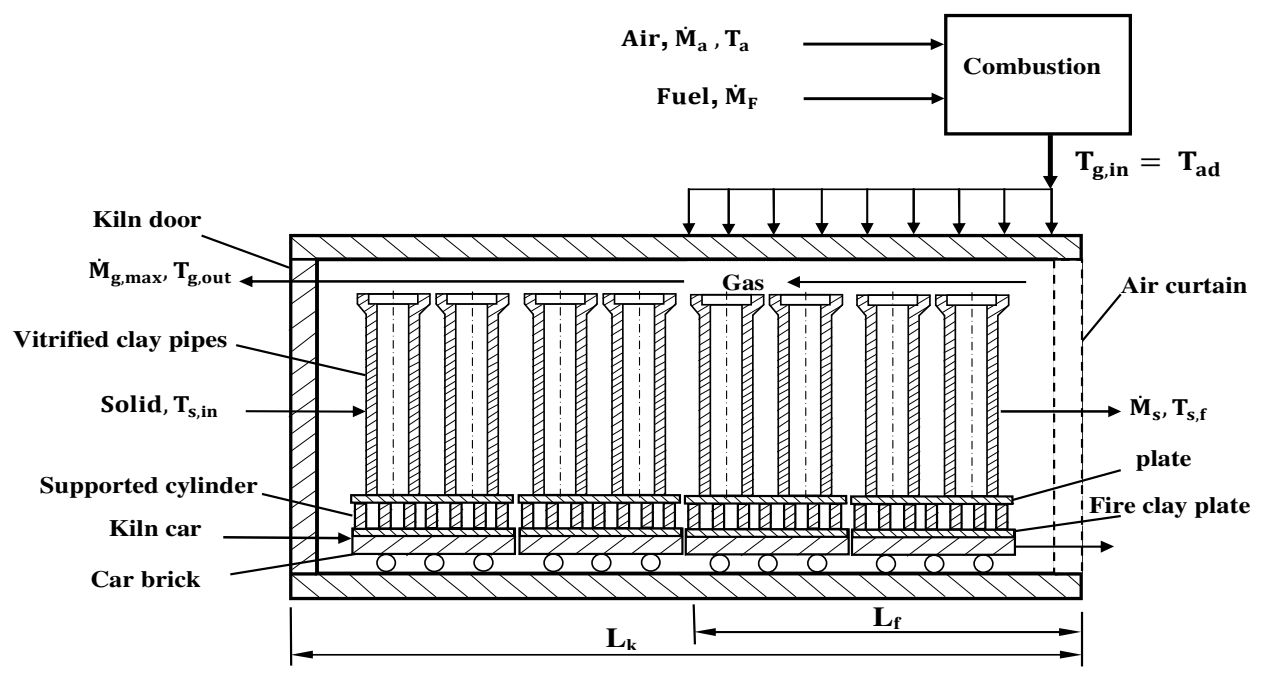

Fig. 1. Schematic description of preheating and firing zones of vitrified clay kiln.

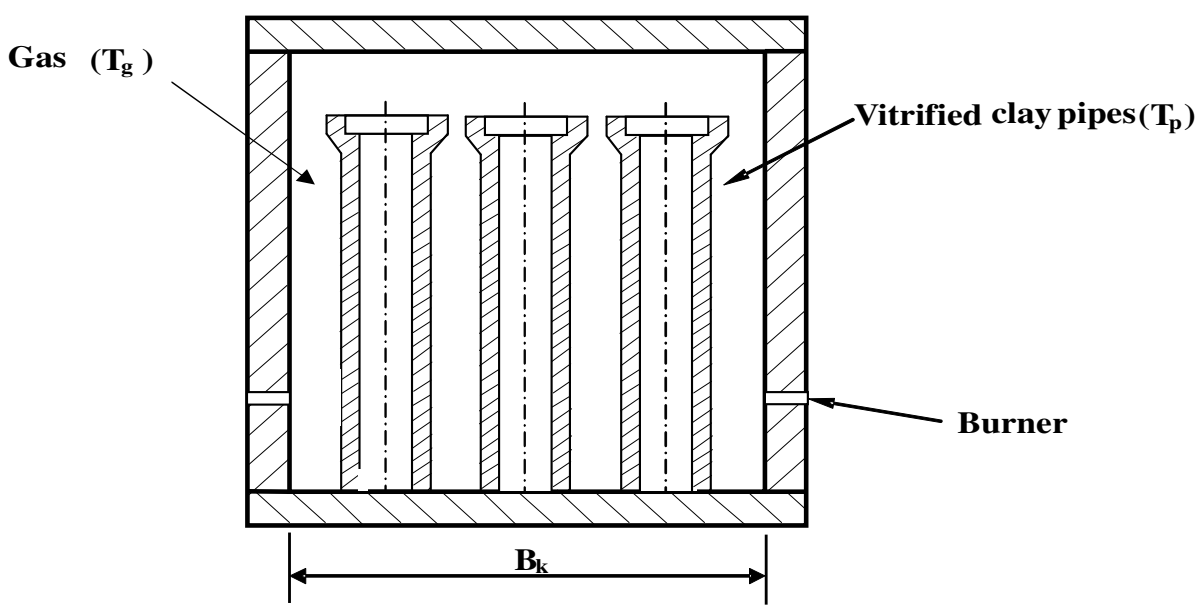

Fig. 2. Cross section view of vitrified clay pipes kiln.

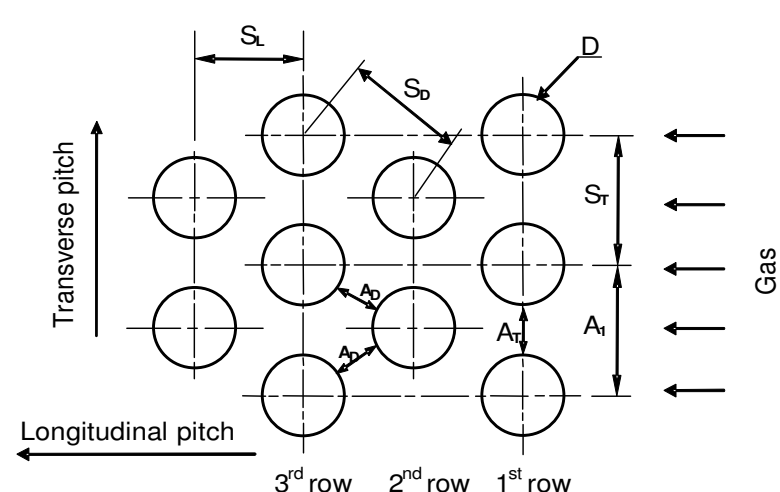

(a)

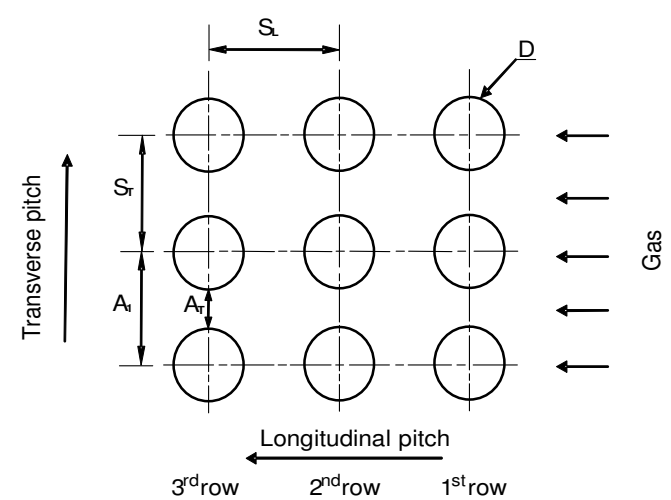

(b)

Fig. 3. Schematic description of the two arrangements (a) Staggered arrangement (b) In-line arrangement. 


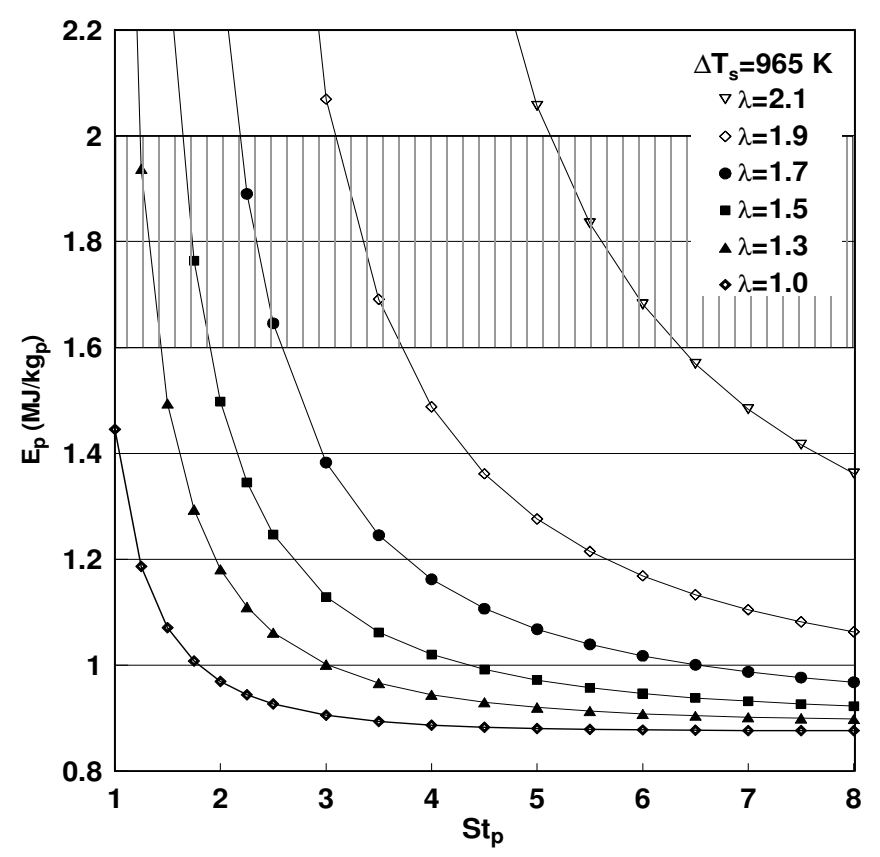

Fig. 4. Energy consumption for vitrified clay pipes kiln.
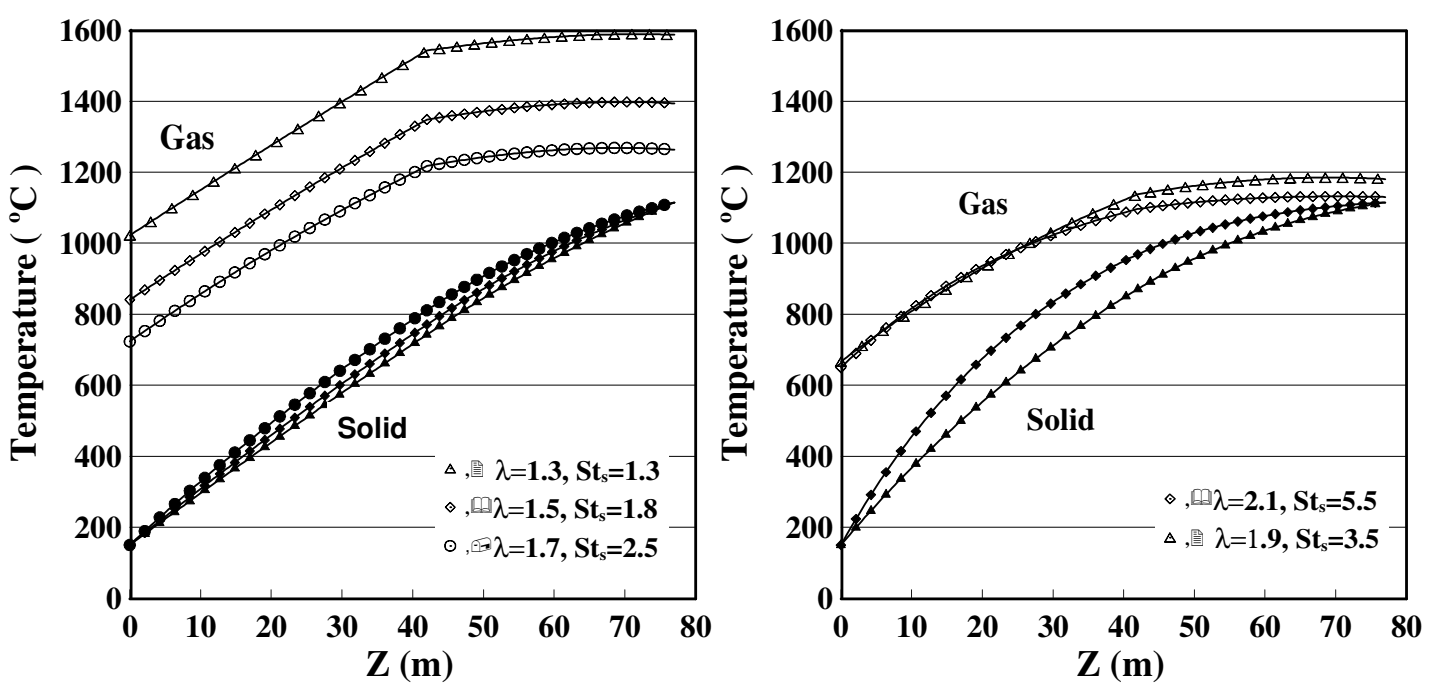

Fig. 5. Temperature profile for different excess air numbers and different Stanton number.
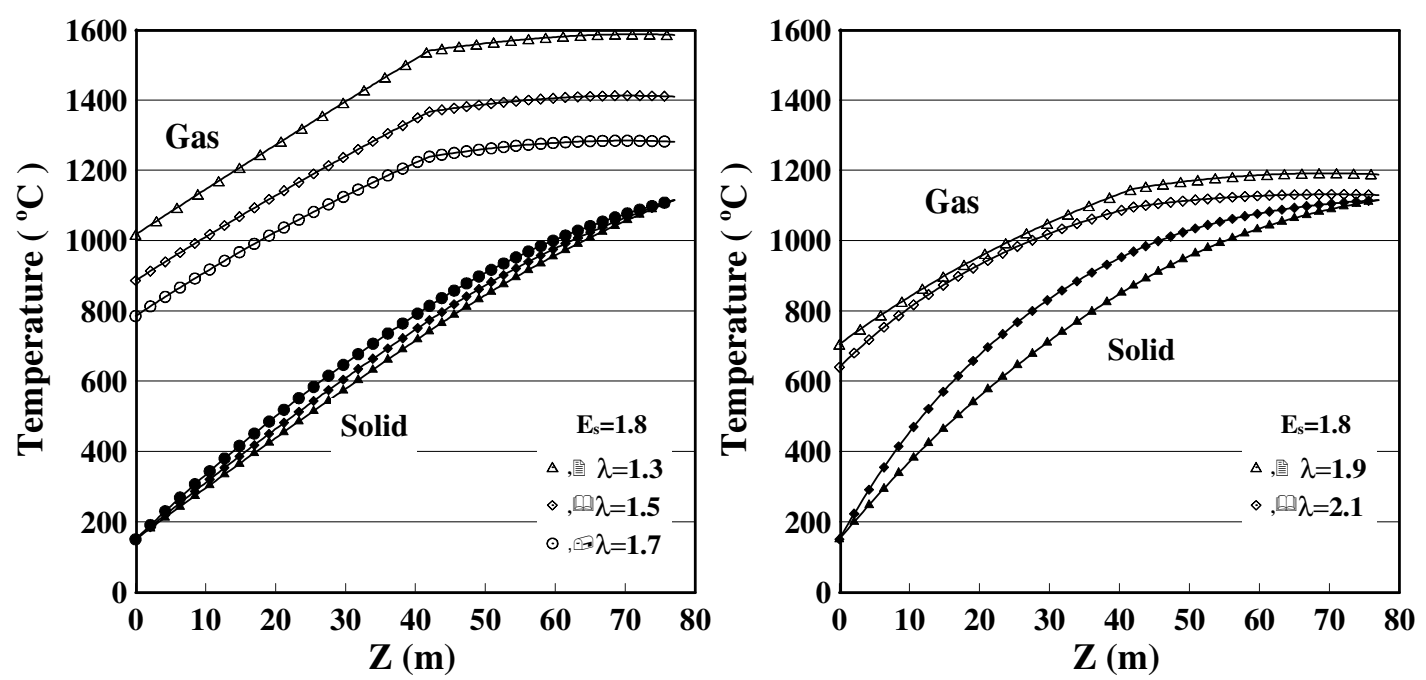

Fig. 6. Effect of excess air numbers on temperature profile with same energy consumption. 

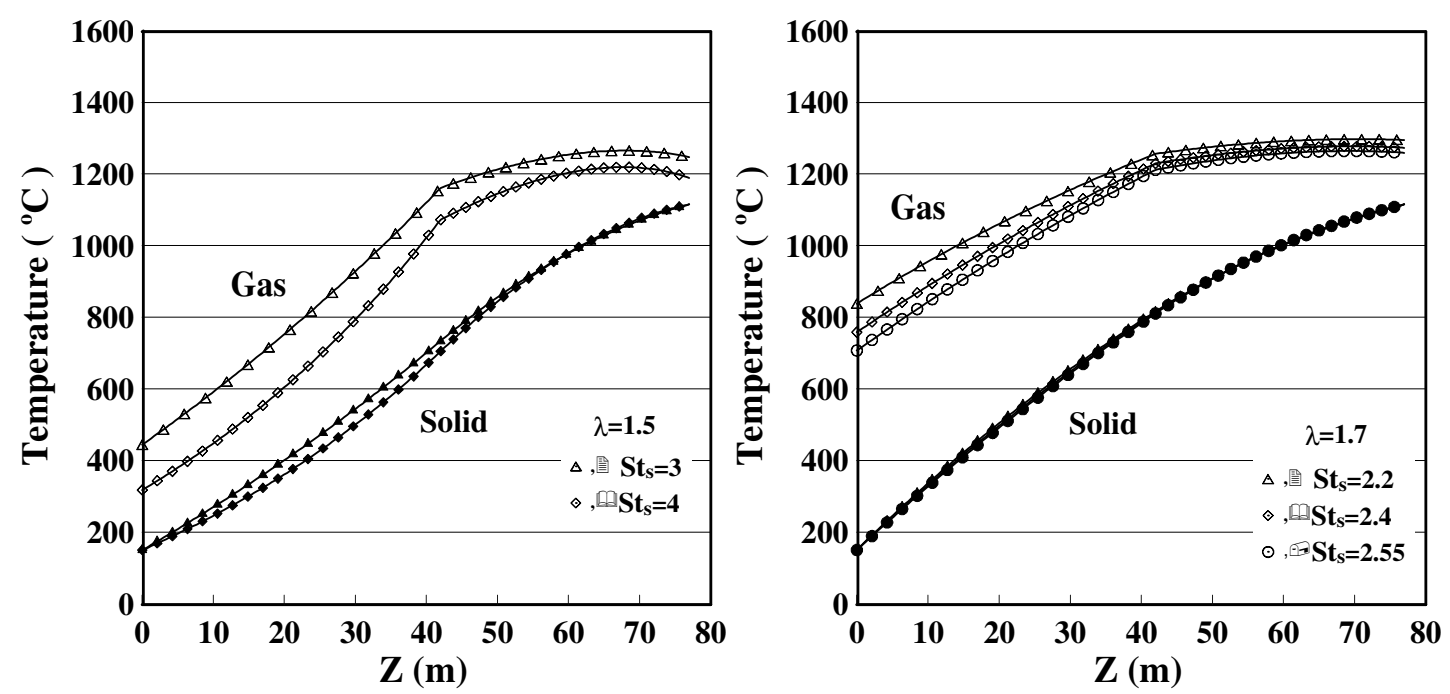

Fig. 7. Effect of Stanton number on temperature profile with same excess air numbers.

Table1. Some data used in calculations.

\begin{tabular}{|c|l|c|c|}
\hline Symbol & \multicolumn{1}{|c|}{ Description } & Value & Unit \\
\hline $\mathrm{B}_{\mathrm{k}}$ & kiln width & 6 & $\mathrm{~m}$ \\
\hline $\mathrm{C}_{\mathrm{s}}$ & specific heat of solid & 0.85 & $\mathrm{~kJ} / \mathrm{kg} \cdot \mathrm{K}$ \\
\hline $\mathrm{H}_{\mathrm{k}}$ & kiln height & 3.5 & $\mathrm{~m}$ \\
\hline $\mathrm{L}_{\mathrm{f}}$ & firing zone length & 35 & $\mathrm{~m}$ \\
\hline $\mathrm{L}_{\mathrm{k}}$ & kiln length & 77 & $\mathrm{~m}$ \\
\hline$\dot{\mathrm{M}}_{\mathrm{p}}$ & pipe capacity in kiln & 20000 & ton/year \\
\hline $\mathrm{T}_{\mathrm{s}, \mathrm{in}}$ & solid inlet temperature & 50 & ${ }^{\circ} \mathrm{C}$ \\
\hline $\mathrm{T}_{\mathrm{s}, \mathrm{f}}$ & solid outlet temperature & 1000 & ${ }^{\circ} \mathrm{C}$ \\
\hline
\end{tabular}

